\title{
Aboriginal and Torres Strait Islander public health: online and integrated into core Master of Public Health subjects
}

\author{
Lynnell Angus, ${ }^{1}$ Shaun Ewen, ${ }^{2}$ Leanne Coombe ${ }^{3}$ \\ ${ }^{1}$ Indigenous Health Equity Unit, Faculty of Medicine, Dentistry and Health Sciences, The University \\ of Melbourne; ${ }^{2}$ Melbourne Poche Centre for Indigenous Health, Faculty of Medicine, Dentistry and \\ Health Sciences, The University of Melbourne; ${ }^{3}$ The University of Queensland, Brisbane, Australia
}

\section{Significance for public health}

This approach to a comprehensive, online, integrated Indigenous public health (IPH) curriculum is significant, as it ensures that all University of Melbourne Master of Public Health (MPH) graduates will have the competencies to positively contribute to Indigenous health status. A workforce that is attuned not only to the challenges of IPH, but also to the principles of selfdetermination, Indigenous agency and collaboration is better equipped to be comprised of ethical and judgment-safe practitioners. Additionally, the outlined approach of utilizing IPH content and examples into core MPH subjects ensures both the Australian relevance for an Australian-based health professional course and international appeal through the modules inclusion of international Indigenous case-studies and content. Furthermore, approaches learned in a challenging Indigenous Australian context are transferable and applicable to other IPH challenges in a local, national and global context.

\begin{abstract}
The Master of Public Health (MPH) is an internationally recognised post-graduate qualification for building the public health workforce. In Australia, MPH graduate attributes include six Indigenous public health (IPH) competencies. The University of Melbourne MPH program includes five core subjects and ten specialisation streams, of which one is Indigenous health. Unless students complete this specialisation or electives in Indigenous health, it is possible for students to graduate without attaining the IPH competencies. To address this issue in a crowded and competitive curriculum an innovative approach to integrating the IPH competencies in core MPH subjects was developed. Five online modules that corresponded with the learning outcomes of the core public health subjects were developed, implemented and evaluated in 2015. This brief report outlines the conceptualisation, development, and description of the curriculum content; it also provides preliminary student evaluation and staff feedback on the integration project.
\end{abstract}

\section{Introduction}

Whilst many Indigenous Australians enjoy good health, the inequitable health status between Indigenous and other Australians is well documented. ${ }^{1}$ As a key strategy to develop an ethical and judgement-safe public health workforce, ${ }^{2}$ the public health education peak body, formerly known as the Australian Network of Academic Public Health Institutions (ANAPHI), established foundational public health competencies in 2009. ${ }^{3}$ An online Delphi process identified the competencies to fulfil key public health functions and a national consultation with public health academics and professionals refined learning out- comes to ensure they were appropriate for Master of Public Health (MPH) graduates. ${ }^{4}$ The approved competency framework consists of six areas of practice. Embedded in this framework is a subset of Indigenous public health (IPH) competencies, which students are expected to demonstrate by graduation..$^{5}$ Table 1 shows where the IPH competencies are required to be addressed across four areas of practice, informed by the National Indigenous Public Health Framework. ${ }^{5}$

This approach to embedding IPH competencies in workforce development reflected pre-existing work undertaken in medical education, with the establishment of an Indigenous health curriculum framework, ${ }^{6}$ and incorporation of Indigenous health accreditation standards for Australian and New Zealand medical schools in 2006. ${ }^{7}$ At the University of Melbourne, from 2014 the MPH program includes five core subjects, electives, and a capstone experience. One of ten specialisation streams is Indigenous health, where students can complete up to five Indigenous health electives and an Indigenous health focused research or professional practice project. In 2011-2013, the Public Health Indigenous Leadership in Education (PHILE) Network conducted a national review of the integration of the IPH competencies in MPH curricula. ${ }^{8}$ In findings from the University of Melbourne MPH review by the PHILE Network, the Melbourne School of Population and Global Health (MSPGH) was commended for its model of vertical integration of Indigenous health, achieved through a diverse range of elective subjects and specialisation. ${ }^{9}$ However, the reviewers recommended that the MSPGH either: i) include a core Indigenous health subject; or ii) integrate the IPH competencies across the core subjects, in order to achieve horizontal integration that would complement the already present vertical integration. This brief report outlines how the University of Melbourne strengthened the integration of IPH competencies into its MPH program.

The following sections outline the development process, description of the curriculum content and preliminary student and staff feedback on the integration project.

\section{Development and description}

In responding to the review recommendations, academics involved with the core curriculum agreed that integrating the IPH competencies across the core subjects was the preferred option (Figure 1). This horizontal integration model is increasingly recommended as best practice in health education. First, it promotes a cross-disciplinary approach to teaching that enables deep rather than superficial learning. ${ }^{10}$ Second, it avoids an ad hoc approach of curriculum delivery where content is: perceived as a tokenistic add-on, consequently devaluing the topic area; ${ }^{11}$ or forgotten as a result of being spread too thinly. ${ }^{12}$ Third, the coordination and planning involved ensures learning outcomes are linked and that 
learning is reinforced in a staged approach. ${ }^{13}$ Finally, it extends responsibility for teaching IPH curriculum content to multiple academics, rather than only to academics responsible for Indigenous health. Integrated core content provides foundational knowledge, which the specialisation subjects can draw upon to extend student learning, and further develop an IPH specialist workforce.

The objectives of the integration project were to: i) develop a core subject and online modules to ensure all graduates meet the IPH competencies; ii) use case-studies to enhance IPH learning outcomes; iii) enable flipping of the classroom and create scaffolded learning to enhance deep knowledge construction; and iv) develop the modules to be delivered separately within the core subjects and adaptable in the future to formulate a coherent online subject.

The case-studies approach was taken so that the horizontal integration of IPH could be identifiable to students as a cross-cutting theme throughout the course. ${ }^{14}$ In public health, case-based learning is emerging as a best practice method of active learning, particularly in online learning environments. ${ }^{15}$ Using case-studies as part of a scaffolded learning approach has also been shown to increase deep knowledge construction. ${ }^{16,17}$ By developing the case-studies online, it provides subject coordinators greater flexibility in their subject delivery, allowing them to flip their classrooms and use face-to-face teaching time for student-driven learning.18

In 2013, this approach was piloted with Public Health in Practice, a core subject at the time in the University of Melbourne MPH. An existing case-study examining trachoma in Indigenous communities was adapted for online delivery and taught in a blended-learning format. Student feedback collected by the subject coordinator regarding this module was positive. This module development process was replicated for the integration project modules.

The IPH competencies were mapped against existing core subject content and learning outcomes by the MPH Working Party. Table 2 shows how content was applied for each core subject and learning outcomes. As the MSPGH MPH program attracts almost half its student enrolments from countries outside of Australia, and to promote the global applicability of Indigenous health, an international Indigenous element was included. Two case-studies were therefore developed for each module: an Australian Indigenous example, and an international Indigenous example.

Content development research was undertaken by the Integration Project Officer. With collaboration and support from IPH experts such as academics, Elders and community members, and IPH sector leaders and managers, multimedia case-studies and supporting materials were identified or developed for each module. As there is no prescribed order

Table 1. The relationship of Indigenous public health competencies to Master of Public Health areas of practice informed by the National Indigenous Public Health Framework.

Area of practice Indigenous public health competency

Health monitoring and surveillance Analyse key comparative health indicators for Aboriginal and Torres Strait Islander peoples.

Analyse key comparative indicators regarding the social determinants of health for Aboriginal and Torres Strait Islander peoples.

Disease prevention and control

Health protection

Health promotion

Describe Aboriginal and Torres Strait Islander health in historical context and analyse the impact of colonial processes on health outcomes.

Critically evaluate Indigenous public health policy or programs.

Health policy planning and management Apply the principles of economic evaluation to Aboriginal and Torres Strait Islander programs with a particular focus of the allocation of resources relative to need.

Evidence-based professional Demonstrate a reflexive public health practice for Aboriginal and Torres Strait Islander health contexts. population health practice

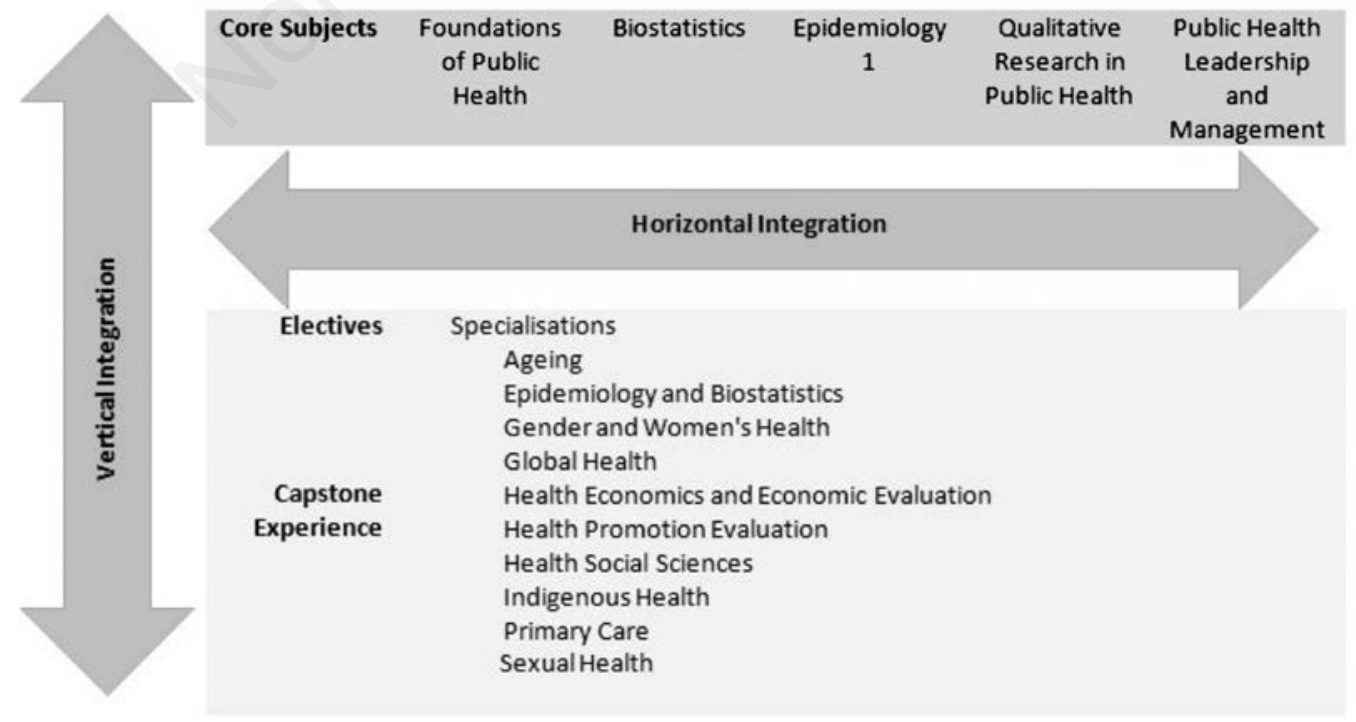

Figure 1. University of Melbourne Master of Public Health Program at March 2016. 
for completing the core subjects, and students can enroll mid-year, each module contained introductory information to orientate students to Indigenous history and the module's relevance for attaining the IPH competencies. Every module included an explanation of, and Welcome to Country by Traditional Owners and Acknowledgement of Country, as well as links to Reconciliation Australia's online cultural respect program. ${ }^{19}$

\section{Implementation}

Once developed, each module was uploaded to the Learning Management System (LMS) and available to students according to the 2015 core subject timetable. Students were introduced to the modules through the subject outline, LMS announcements, at lectures by the subject coordinators and student MPH orientation days. Students were required to access the modules as preparation for lectures, tutorials and/or assessments in line with learning outcomes and activities.

Implementation was also supported by a close collegial approach by academics involved in the course. The Integration Project Officer worked closely with subject coordinators and actively participated in the MPH Working Party to support seamless and collegial implementation of the modules into the subject learning outcomes. One of the key challenges of the project was engaging with subject coordinators across a diverse range of subjects and different disciplines to develop content that was coherent and consistent to enable student recognition of the IPH cross-cutting theme. A co-learning approach was required, such that academics were open to learn across, from, and outside of their usual disciplines.

\section{Preliminary evaluation}

Informal feedback from the MPH Working Party and preliminary student evaluation has informed the implementation of the modules in 2016. The feedback from staff included the importance of a dedicated resource to progress the work and enable timely implementation.
Further staff comments included improving access to content expertise, and acknowledged that the collaborative, co-learning approach broadened people's knowledge of IPH. Preliminary student feedback indicated: the importance of the case studies and supporting materials for increasing their knowledge of Indigenous peoples as well as the impacts of colonisation and IPH; there was application for what was learned to Indigenous peoples from outside Australia and other minority groups; usefulness for assessments in other subjects and future public health practice; increasing opportunities for face-to-face teaching and discussion of the material; explaining rationale for the IPH modules; inclusion of an Australian history lesson at beginning of each subject.

\section{Future steps and conclusions}

The next phase of the project includes the following objectives: i) conduct more rigorous and comprehensive evaluation of module content and achieved student learning outcomes; ii) further develop existing modules, such that they are accessible to the broader Australian public health workforce; iii) develop the five modules as a coherent whole subject that can be taken separately to the MPH; iv) consider developing a Massive Open Online Course (MO0C), on the basis of the existing online content.

To ensure that Australian higher education health graduates are equipped to address challenges presented by disparities in health status and outcomes between Indigenous and non-Indigenous peoples, students must have opportunities to learn and deepen their Indigenous health knowledge and its application. Equipping students also involves deepening their understanding of social and historical conditions as well as addressing biases that continue to perpetuate disadvantage. Enabling students to demonstrate their attainment of graduate attributes including the IPH competencies remains a significant pedagogical challenge across the health sciences, no-less-so for public health students. Training a public health workforce equipped to meet the immediate and future challenges of a multicultural community, nation or nations is a primary purpose of MPH programs.

Table 2. Integrated Indigenous public health content in the University of Melbourne Master of Public Health (MPH).

\begin{tabular}{|c|c|c|c|c|}
\hline MPH core subject & Content area & Learning outcome & Australian example & International example \\
\hline $\begin{array}{l}\text { Foundations of public } \\
\text { health }\end{array}$ & $\begin{array}{l}\text { Indigenous population } \\
\text { health }\end{array}$ & $\begin{array}{l}\text { Describe application } \\
\text { of population health approaches, } \\
\text { including Australian and international } \\
\text { Indigenous health }\end{array}$ & $\begin{array}{l}\text { Victorian Aboriginal } \\
\text { community controlled primary } \\
\text { health care }\end{array}$ & $\begin{array}{l}\text { Mapuche community controlled } \\
\text { hospital }\end{array}$ \\
\hline Epidemiology & $\begin{array}{l}\text { Study design with } \\
\text { Indigenous peoples }\end{array}$ & $\begin{array}{l}\text { Recognise the roles, strengths, } \\
\text { weaknesses and ethical } \\
\text { conduct of study designs }\end{array}$ & $\begin{array}{l}\text { Remote Aboriginal } \\
\text { cohort study }\end{array}$ & $\begin{array}{l}\text { Ethical considerations of } \\
\text { First Nations } \\
\text { youth }\end{array}$ \\
\hline Biostatistics & $\begin{array}{l}\text { Calculations and } \\
\text { interpretations } \\
\text { in studies with } \\
\text { Indigenous peoples }\end{array}$ & $\begin{array}{l}\text { Conduct and interpret } \\
\text { calculations in studies } \\
\text { with Indigenous peoples }\end{array}$ & $\begin{array}{l}\text { Pragmatic RCT with } \\
\text { Aboriginal women in } \\
\text { South Australia }\end{array}$ & $\begin{array}{l}\text { Breast cancer among } \\
\text { Maori women }\end{array}$ \\
\hline $\begin{array}{l}\text { Qualitative research } \\
\text { in public health }\end{array}$ & $\begin{array}{l}\text { Indigenous research } \\
\text { ethics and decolonising } \\
\text { methodologies }\end{array}$ & $\begin{array}{l}\text { Understand ethics } \\
\text { underpinning public health } \\
\text { research, in particular } \\
\text { ethics of research with } \\
\text { Indigenous communities }\end{array}$ & $\begin{array}{l}\text { History and development } \\
\text { of ethics in Aboriginal } \\
\text { and Torres Strait Islander } \\
\text { research }\end{array}$ & $\begin{array}{l}\text { Kaupapa principles } \\
\text { and evaluation of a Maori } \\
\text { community-based, } \\
\text { diabetes prevention program }\end{array}$ \\
\hline $\begin{array}{l}\text { Public health leadership } \\
\text { and management }\end{array}$ & $\begin{array}{l}\text { Indigenous public } \\
\text { health leadership } \\
\text { and management }\end{array}$ & $\begin{array}{l}\text { Apply knowledge of Indigenous } \\
\text { culture and values to public } \\
\text { health leadership and management } \\
\text { in complex settings }\end{array}$ & Indigenous Gathering Place & $\begin{array}{l}\text { Displaced Karen people } \\
\text { living in a closed camp }\end{array}$ \\
\hline
\end{tabular}


Correspondence: Lynnell Angus, Level 4, 207 Bouverie Street, Carlton Victoria 3010, Australia. Tel.: +61.3.8344.3368.

E-mail: lynnell.angus@unimelb.edu.au

Key words: Indigenous public health; Aboriginal and Torres Strait Islander; Master of Public Health; higher education.

Acknowledgements: authors would thank Professor Kerry Arabena for providing supervision and direction for the development of the modules, and the University of Melbourne Master of Public Health Working Group for their collaboration on the integration project. Thanks to Auntie Diane Kerr, Wurundjeri Elder, Ms Emily Munro-Harrison and Mr Alister Thorpe, Research Fellows, Indigenous Health Equity Unit and Mr Peter Ferguson, Lecturer in Indigenous Rural Health Studies and Strategic Development and Research, Rural Health Academic Centre for reviewing the online modules for cultural respect. Please note: In acknowledging the diversity of Aboriginal and Torres Strait Islander peoples, the use of Indigenous is as a collective term that encompasses and does not attempt to homogenise the many distinct and unique cultures and identities.

Contributions: LA, management of integration of the Indigenous public health competencies into the core Master of Public Health subjects, collaborating with a range of stakeholders to plan, develop, implement and evaluate the online modules and made significant contributions to drafting and finalising the article; SE, LC, conceptualisation, development, and implementation of Indigenous health teaching and learning at the University of Melbourne, significant intellectual input into the concept, design and attaining a grant for the integration of the Indigenous public health competencies as well as advancing the interpretation of the article.

Conflict of interest: the authors declare no potential conflict of interest.

Received for publication: 15 January 2016.

Accepted for publication: 9 March 2016.

(C) Copyright L. Angus et al., 2016

Licensee PAGEPress, Italy

Journal of Public Health Research 2016;5:675

doi:10.4081/jphr.2016.675

This work is licensed under a Creative Commons Attribution NonCommercial 4.0 License (CC BY-NC 4.0).

\section{References}

1. NACCHO. Close the gap: solutions to the indigenous health crisis facing Australia. Melbourne: Oxfam Australia; 2007.

2. Durham G, Plant A. Strengthening workforce capacity for population health (phase III PHERP review 2005). Canberra: Commonwealth Department of Health and Ageing, 2005.

3. Genat B, Robinson P, Parker E. Foundation competencies for Master of Public Health Graduates in Australia. Australian Network of Academic Public Health Institutions, 2009.
4. Genat B, Robinson P. New competencies for public health graduates: a useful tool for course design. Aust N Z J Public Health 2010;34:513-6.

5. Genat B. National indigenous public health curriculum framework. Melbourne: Onemda VicHealth Koori Health Unit, The University of Melbourne; 2008.

6. Phillips G. CDAMS indigenous health curriculum framework. Melbourne: VicHealth Koori Health Research and Community Development Unit, The University of Melbourne, 2004.

7. AMC. Assessing specialist medical education and training Canberra: Australian Medical Council; 2016.

8. Lee V, Coombe L, Robinson P. Building capacity through action research curricula reviews. Higher Educ Res Dev 2015;34:324-37.

9. Anders W, Muscat M, Jessen J. Review of the University of Melbourne Master of Public Health Program. Melbourne: Onemda VicHealth Koori Health Unit, The University of Melbourne, 2013.

10. Dahle LO, Brynhildsen J, Behrbohm Fallsberg M, et al. Pros and cons of vertical integration between clinical medicine and basic science within a problem-based undergraduate medical curriculum: examples and experiences from Linköping, Sweden. Med Teach 2002;24:280-5.

11. Rasmussen L. Towards reconciliation in aboriginal health. Melbourne: VKHRCDU, The University of Melbourne; 2001.

12. Kai J, Spencer J, Wilkes M, Gill P. Learning to value ethnic diversity: what, why and how? Med Educ 1999;33:616-23.

13. Vidic B, Weitlauf HM. Horizontal and vertical integration of academic disciplines in the medical school curriculum. Clin Anat 2002;15:233-5.

14. Kitzes JA, Savich RD, Kalishman S, et al. Fitting it all in: integration of 12 cross-cutting themes into a school of medicine curriculum. Med Teach 2007;29:489-94.

15. de Jong N, Verstegen D, Tan F, O'Connor S. A comparison of classroom and online asynchronous problem-based learning for students undertaking statistics training as part of a public health masters degree. Adv Health Sci Educ 2013;18:245-64.

16. Darabi A, Arrastia MC, Nelson DW, et al. Cognitive Presence in asynchronous online learning: a comparison of four discussion strategies. J Comput Assist Learn 2011;27:216-27.

17. Jeffries $C$, Maeder DW. The effect of scaffolded vignette instruction on student mastery of subject matter. Teach Educ 2009;44:21-39.

18. Herreid C, Schiller N. Case studies and the flipped classroom. J Coll Sci Teach 2013;42:62-6.

19. Reconciliation Australia. Share our pride. Available from: http://www.shareourpride.org.au/. 